\title{
Research on Planning and Management of Urban Parking Lot-Taking Hangzhou as an Example
}

\author{
Shanshan Yang, Lixia Huang \\ Zhejiang Agriculture \& Forestry University, Hangzhou, China \\ Email:yssxia0xia0@163.com
}

How to cite this paper: Yang, S. S., \& Huang, L. X. (2017). Research on Planning and Management of Urban Parking Lot-Taking Hangzhou as an Example. Current Urban Studies, 5, 379-386. https://doi.org/10.4236/cus.2017.54021

Received: October 9, 2017

Accepted: November 14, 2017

Published: November 17, 2017

Copyright $\odot 2017$ by authors and Scientific Research Publishing Inc. This work is licensed under the Creative Commons Attribution International License (CC BY 4.0).

http://creativecommons.org/licenses/by/4.0/

\section{(c) (i) Open Access}

\begin{abstract}
With the increasing number of city cars, traffic jams and parking difficulties have become a bottleneck of urban development. Creating the conditions to achieve the dynamic balance between road and automobile resources and allocate the parking resources reasonably is not only beneficial to the rapid development of cities, but also convenient for people to travel by bus or car. It can also ensure orderly parking, implementation of normative management, which can solve the problem of traffic jam and parking difficulties thoroughly. This paper takes the city of Hangzhou as an example, discussing the existing problems and countermeasures in urban parking planning and management. This paper first analyzes the existing problems in Hangzhou parking management from aspects, such as the serious shortage of parking lots, the lack of a clear management body, the inefficient use of car parks in some areas and lack of a long-term mechanism to attract social forces to participate in car park construction, and then proposes solutions to the problems from different aspects, such as giving full play to the pilot role of urban parking planning and management, establishing and improving the mechanism on parking lot management, and introduces social forces to participate in the construction and management of car parks, which provides reference for the planning and management of urban parking lot in China.
\end{abstract}

\section{Keywords}

Urban Parking Lots, Planning, Management, The City of Hangzhou, Problems, Countermeasures

\section{Introduction}

In recent years, with the acceleration of urbanization, China has gradually en- 
tered the era of new urbanization. At the same time, as a necessary means of transportation, cars have crept into most of the families in cities. With the increasing number of city cars, traffic jams and parking difficulties have become a bottleneck in urban development (Ministry of Land and Resources of the Ministry of Housing and Urban-Rural Development, 2016). For big cities, creating the conditions to achieve the dynamic balance between road and automobile resources, equipping with a parking space suitable for urban development, and solving the problem of traffic jam and parking difficulties thoroughly, are not only beneficial for the rapid development of the city, but also bring convenience to people's travel. It can effectively improve the operation efficiency of the city and the quality of life of the residents if we vigorously strengthen planning and management of urban parking lots and allocate the parking resources reasonably to achieve the normative management. It can also promote the development of the city into the fast lane (Wang, 2014). Like other modern metropolises in our country, the city of Hangzhou also faces problems of parking lot planning and management. In this case, researching on the existing problems in the parking lot planning and management in the city of Hangzhou can not only solve the problem of parking difficulties in the city of Hangzhou, but also provide reference to parking lot planning and management in other cities in our country.

\section{The Existing Problems in the Planning and Management of the Parking Lot in the City of Hangzhou}

\subsection{A Serious Shortage of Parking Lots}

As a modern city, the motor vehicles in the city of Hangzhou are increased by about $15 \%$ every year. And the purchase of private cars is becoming more. But because Hangzhou is developing rapidly, the urban construction land is not enough, and the parking lot planning management lags behind, which lead to prominent contradictions between car park construction and motor vehicle number growth. Under normal conditions, the ratio of urban parking Spaces to the total amount of cars should be 1.3:1 to meet the needs of parking, and the number of parking Spaces and cars in government departments and communities should be 1:1, and the parking Spaces for commercial parking must reach a third of the number of cars. By June 2017, Hangzhou has about 2.38 million vehicles, but it only has about 1.2 million parking space. That is to say, the ratio of number of cars to the number of parking spaces in Hangzhou is 1.98:1, far from meeting the demand for city parking (Chengpin, 2017). Besides, due to the differences in economic development between the constructions of old and new communities, there are also different parking Spaces in each community. Compared to the new communities, the old communities face the problem of a serious shortage of parking spaces. Even in new communities, there are few parking Spaces, and it is difficult to meet the demand for parking. Investigation reveals that the nighttime parking Spaces in the downtown area are much tenser. 
In some communities, the parking gap is even more than 40 percent. For example, For example, there are 27 communities in the Xiaoying street, among which there are 27 communities with property management and 6 old residential districts. The actual parking quantity in the peak of the old districts is more than 1500. But as the old residential districts lack berth planning conditions, there are only 223 regular public parking spaces on the road. After completing the road improvement in the university road, there are 457 new berths in the old residential districts and the standard parking space reaches 680 . However, there are still more than 800 parking spaces are needed. It is just because parking lot planning and management lags behind, that there are many social problems like parking shortage, parking difficulties, parking disorderly and traffic jam. The problems bring hidden trouble to the security development of the city of Hangzhou, and also restrict the normal development of Hangzhou.

\subsection{The Parking Lot Lacks a Clear Plan Management Body}

As a big city, the parking lot in Hangzhou is distributed extensively, and its type is complex. There are roadside parking lots, off-road car parks, parking lots with buildings, public car parks, and special parking lots. Those parking lots are located in different places in Hangzhou, occupying different Spaces of the city, and the units involved are also more complex. Many departments such as municipal, traffic, public security, traffic police, urban management, planning, construction, industry and commerce, taxation, price, environmental protection and so on may participate in the process of approval, planning and construction of the parking lots. These departments have different rights of approval, planning, construction and management, and the powers of each department are crisscrossed. Their responsibilities are not clear. Some departments have the right of approval but have no power of management. Some departments have the right of management, but no right of approval. For example, the municipal and planning authorities have the right of approval, but have no right of management, while the administrative department of urban management has the right of administration, but no right of approval. So the responsibility is not clear that who should plan and mange the construction of parking lots. What is the number of cars in different areas of the city, and how many parking spaces could meet the demands for parking? It lacks a systematic investigation, which will lead to chaos in urban parking planning and management. The construction of city car parks cannot be carried out in an orderly way, in which circumstance many parking lots are under the control of not clear relationship. So there are a lot of price hikes and fees.

\subsection{The Use of Car Parks in Some Areas Is Inefficient}

Although China has entered the market economy very early, Hangzhou still retains the features of the planned economy in setting up the parking lot charge 
standards, which means the parking fee is set by the government instead of adopting social and market-based ways to organize public hearings, which leads to higher charging standards in hospitals, stations and airports, and the result of the high rate of parking space is that the roadside parking phenomenon in the above areas is serious. Besides, in the parking space approval process, the government lacks macro planning, allocates the parking resources unreasonably and builds more roadside parking Spaces around professional parking lots, which leads to fewer cars parking in professional parking lots, even the phenomenon of "empty field" occurs. This not only wastes the parking resources, but also brings loss to the professional parking lots. Third, some units and some residential areas executes a closed-end management, the parking Spaces are only for internal use, which directly leads to a considerable number of vehicles parked on the roads around these units and communities and causes traffic jam. Fourth, the price difference in the underground parking space and overground parking space is too big, which causes many underground parking Spaces are vacant. In some communities, the usage fee of the overground parking lots is about 5000 CNY per year, while the usage fee of the underground parking lots is about 20,000 CNY per year. Facing such a big difference in price, many car owners choose the overground parking lots instead of the underground parking lots, even though the underground parking lots are safer and environment is better, which waste the underground parking lots.

\subsection{A Lack of the Long-Term Mechanism to Attract Social Forces to Participate in Car Park Construction}

The parking lots not only have the properties of urban public welfare facilities and urban infrastructures, but also have commercial properties. But during the planning and management process of Hangzhou parking lots, much attention is paid to the properties of urban public welfare facilities and urban infrastructure, and very little attention is paid to its business properties. That is to say the builders and managers of the parking lots in Hangzhou are Hangzhou municipal government and its related units, and the use of car parking lots is mostly public with few other social forces are involved. In the city of Hangzhou, the operating units of the parking lots are mainly state-owned enterprises, accounting for about 90 percent of all parking lots and about $9 \%$ of the collective ownership units. Other social forces are only around 1\%. Although Hangzhou city has issued a series of policies in recent years to attract other social forces to participate in the construction of urban parking lots, most are only at the policy level, and real institutional arrangements and policy supports have not been formed. Especially under the conditions of the long term free parking or low-price parking, people cannot accept expensive parking fee ideologically, which makes the social forces who could involve in the construction of city parking lots worry too much. Thus, the social forces involved in the construction of urban parking lots are seriously less. 


\section{The Countermeasures of Solving the Problems of Urban Parking Planning and Management in Hangzhou}

\subsection{To Give Full Play to the Pilot Role of Urban Parking Planning and Management}

To give full play to the pilot role of urban parking planning and management, the number and scale of parking Spaces must be reasonably determined at first. The number of city car ownership and its daily use status are the keys to determine the number and size of urban parking Spaces. The number and size of parking Spaces in residential areas are determined by the amount and use of the car, while the number and size of parking Spaces in work and other areas are directly related to the mode of transportation. Therefore, to determine the number and scale of parking Spaces reasonably, investigation and research must be carried out, the total amount of car ownership and the use status of cars in different areas should be mastered, then the ratio of on-street parking and off-street parking should be determined according to the international standards (Ma, Wu, \& Gao, 2014). Secondly, we should study the allocation standards of parking spaces for new and expanded projects. As the parking space of the above construction projects occupies a big proportion of all the parking Spaces, a reasonable standard for parking spaces should be made according to the total demand of parking space and use of area and land strictly (Zeng, 2017). Thirdly, planning for construction of more public parking lots in areas with insufficient parking spaces should be made. Because there is a lack of equipped parking spaces in previous construction projects, which causes poorly allocated parking spaces, then it leads to the parking difficulty in those areas. So in the planning process, we should make correlative plans, determine the number, size, location and parking method in order to conduct overall and comprehensive consideration, formulate the implementable plans based on the regional land use, so as to make up for the lack of parking spaces in the area. Fourth, in combination with the long-term development of the city, we should formulate the planning scheme of public parking lots in transportation hubs and prosperous areas. At present, China's urbanization construction is in the ascendant, many cities have made long-term development plans, and the rail transit and rapid transit system are integrated in city planning. In the construction of city car parks, the long-term development of the city must be taken into account, the urban parking lots should be incorporated into the urban development planning in order to reserve sufficient space for the construction of the future comprehensive transportation system (Wang, 2016).

\subsection{Establish and Improve the Parking Lot Planning and Management Mechanism}

To establish and improve the parking lot planning and management mechanism, a unified governing body must be established firstly. As the parking lot management policy involves many departments, it is difficult to coordinate the re- 
lated departments, which leads to a series of problems during the construction, management, operation and other process of parking lots (Liu, 2015). So, a unified urban parking coordination management agency must be established to coordinate the relationships between municipal, traffic, public security, traffic police, urban management, planning, construction, industry and commerce, taxation, price, environmental protection and other departments. Clarify their rights of approval and management, make the overall planning of city car parks, formulate the urban parking system and related laws and regulations, exert the rights of planning, approval, capital preparation, construction and management of the parking lots, and hold hearings to set prices and monitor the price of parking lots to improve the planning and management of car parks and promote the parking of car parks going orderly (Shen, 2016). The management should also coordinate relevant departments, develop management regulations and methods and strictly supervise the implementation of the regulations and methods. The management departments should strengthen the management of parking lots, strictly follow the management system of the parking lots, and strengthen the unified management of business license management, road parking space planning, parking lots setting, facilities and other contents, seriously deal with illegal parking, cancel the temporary parking spaces on the surrounding roads of less used car parking lots and improve the management level of car parking lots to create a favorable environment for the development of the parking industry. In addition, the management departments should carefully check the using natures of the parking lots, ask the units or individuals that are not in accordance with standards or are not equipped with parking Spaces to correct according to the planning standards. Those who fail to correct within the time limit shall be punished strictly according to the provisions. The management departments should also strictly supervise the operation of the parking lots and maintain the operation order of the parking lots while regulating its parking service to ensure the orderly development of the parking industry (Sui, $\mathrm{Yu}, \&$ Wang, 2013). To establish and improve the parking lot planning and management mechanism, we will also need to set up a parking lot research consultancy. Because the city construction is in dynamic development, previous policies are difficult to adapt to the needs of urban developments, so a scientific research advisory body must be established for this purpose to evaluate the direction and trend of development of urban vehicles, prepare the parking lots according to the actual situation, formulate, revise and adjust relevant policies and regulations, and guide the planning and management of city parking lots (Zhang, Yang, \& Qiu, 2015).

\subsection{Introduce Social Forces to Participate in the Construction and Management of Car Parking Lots}

To promote the marketization and industrialization of car parking lots, competition mechanisms and parking service enterprises with normative service and 
advanced technology must be introduced, so as to actively support local parking enterprises and completely change the mode of government departments in charge of the construction and their subordinate units monopolized operation (Pan, 2013). In attracting social forces to participate in the construction and management of car parking lots, Hangzhou has begun a bold attempt. To promote the planning and construction of motor vehicle parking lots in Hangzhou, regulate car parking lots (library) management, meet the parking demands, improve traffic conditions and ensure the coordinated developments of urban traffic, the Hangzhou government has formulated the regulation of construction and administration of motor vehicle parking lots in Hangzhou in the year of 2013. The regulation points out that public car parking lots' construction adopts the mode of government and social forces investing together. The government encourages social forces to invest in the construction of public parking lots in the principle of "who invests, who benefits", provide the policy support to the social forces' investment for the planning, construction and operation of public parking lots, and formulate preferential policies of tax reduction and government subsidies and so on. The Hangzhou municipal government issued the "implementation measure for encouraging and promoting the industrialization of public car parks in Hangzhou" in 2014. The measure provides that the investment units can not only set up advertising space in the parking lots to recoup funds, but can also have property rights. It is noteworthy especially that within the term of operation, the parking fee is also regulated by the market, and investment units could set their own prices according to the principle of tax payment and reasonable profit. Thus, the price of parking lots in prime location is likely to be slightly higher than the government price. For investors, recycling cost becomes faster. It is also an effective way to relieve congestion in the city center.

\section{Conclusion}

In conclusion, with the acceleration of urbanization, China's urban cars will also gradually increase, which will bring some pressure to our city management. At present, the planning, construction and management of urban parking lot in China are still in the developmental stage, and there are many problems. Under this circumstance, managers of different cities should carefully analyze their own developmental advantages and existing problems, learn from the advanced parking lots planning and management experience at home and abroad and combine it with local reality in order to develop a parking lot's management plan that meets the local development situation. Only in this way can the demand of urban development be met, the bottleneck of traffic jams and parking difficulties for urban development be broken, and the way for the orderly development of the city be paved. This study takes Hangzhou as an example, analyzes the existing problems of urban parking lot planning and management in Hangzhou and puts forward some methods and suggestions to solve the problems. This research 
is based on facts, and the research results not only provide references for solving the problems of urban parking lot planning and management but also have certain significance of reference for relevant academic research.

\section{Project}

Project title: University student science and technology innovation program and new talent seedling project in Zhejiang province: the application of PPP model in Hangzhou city's law enforcement management (2017R412047).

\section{References}

Chengpin, X. M. (2017). By June 17, There Were 23 Cities in China with More than 2 Million Vehicles. http://mmgoodcar.com/story/3/495.html

Liu, J. (2015). A Preliminary Study on the Problem of Parking Lot in Huangdao District, Qingdao. Journal of Weifang College, 15, 60-63.

Ma, X. F., Wu, C. Z., \& Gao, Y. (2014). The Planning Model of Parking Expansion Based on Uncertainty Theory. Journal of Wuhan University of Technology: Transportation Science and Engineering, 38, 984-988.

Ministry of Land and Resources of the Ministry of Housing and Urban-Rural Development. (2016). Notification Links of Ministry of Land and Resources of the Ministry of Housing and Urban-Rural Development on the Improvement of Urban Parking Lot Planning and Land Use Policy: How to Use Policy for Parking Lots. Land and Resources Communications, 4, 24-29.

Pan, M. M. (2013). Analysis on Planning and Design of Ecological Parking Lot in Urban Parks-Take the Ecological Parking Lot in Yanan Northwest Chuan Mountain Park as an Example. China Garden Digest, 29, 143-144.

Shen, L. H. (2016). Three-Dimensional Parking Lot Planning and Design-Discussion on Parking Planning in Intensive Land Mode. Traffic \& Transportation, 32, 112-116.

Sui, C. G., Yu, X. T., \& Wang, J. (2013). Discussion on the Optimization of Layout of Social Parking Lot in the Central Area of Jinan. Urban Road Bridge and Flood Control, 8, 24-26.

Wang, T. (2014). Analysis on the Case of Planning and Design of Urban Commercial Buildings Parks. Shanxi Architecture, 40, 18-19.

Wang, Y. (2016). Research on Planning and Design of Parking lots-Take Baoying County as an Example. Technical Innovation Guide, 13, 40-41.

Zeng, L. (2017). The Planning and Exploration of Public Parking Lot under the Bridge of the Main Urban Area in Chongqing. Modern Commercial Industry, 38, 177-178.

Zhang, Y., Yang, L., \& Qiu, Z. (2015). The Design Strategy of Motor Vehicle Parking Lot in Colleges and Universities-Take the Planning and Design of Huaihai Institute of Technology as an Example. Urban Architecture, 11, 3. 